\title{
Clinical experience with use of ultrasound sphygmomanometer
}

\author{
C. F. George, P. J. Lewis, and Aviva Petrie \\ From the M.R.C. Clinical Pharmacology Research Group, Royal Postgraduate Medical School, London; \\ and Department of Medical Statistics, London School of Hygiene and Tropical Medicine, London
}

The performance of an ultrasound sphygmomanometer (Arteriosonde I217) has been compared with that of the London School of Hygiene and Tropical Medicine and Hawksley sphygmomanometers. The Arteriosonde gave closely similar values of systolic blood pressure to the other instruments but diastolic blood pressure lay midway between phase 4 and phase 5 of the Korotkoff sounds. Observers using the Arteriosonde showed a significant preference for even terminal digits.

Measurement of arterial pressure by conventional sphygmomanometer is subject to several sources of error. These include faults in the instrumentation and the use of an occluding cuff of incorrect size. However, the main sources of error lie with the observer and are of two sorts; those caused by bias and those by uncertainty in interpreting the Korotkoff sounds. Bias on the observer's part can be reduced or eliminated by using either the London School of Hygiene and Tropical Medicine sphygmomanometer (LSHTM) described by Rose, Holland, and Crowley (1964) or the random zero (Hawksley) sphygmomanometer (Wright and Dore, 1970). When using these instruments the observer remains in ignorance of the reading until the operation is completed and hence bias and terminal digit preference are reduced.

Difficulties in interpreting the Korotkoff sounds are an important source of intra- and interobserver differences in measuring blood pressure and neither the Hawksley nor the LSHTM machine offer a solution to this problem. An alternative method of indirect sphygmomanometry was proposed by Ware (1965) in which movements of the arterial wall distal to the occluding cuff are measured not by auscultation but by ultrasound. A sphygmomanometer using this principle is now commercially available. Since the machine operates automatically, all observer bias should be eliminated, with obvious applications to epidemiological and pharmacological studies. In this study we have formally compared the machine, the Arteriosonde (Kontron

Received 30 October 1974.
Instruments Ltd.) with the LSHTM and the Hawksley machines.

\section{The instrument}

A detailed description of the instrument has been given by Gruen (1968, 1969). The Arteriosonde 1217 is housed in an instrument case measuring $39 \times 31 \times 31$ $\mathrm{cm}$ (Fig. I). The instrument, which weighs about $18 \mathrm{~kg}$ is connected by a cable assembly to a standard sphygmomanometer cuff which incorporates the ultrasound transducer (Fig. 2). A thin layer of ultrasonic coupling medium is applied to the transducer, which contains a series of ultrasound generators and receivers, and the cuff is placed on the upper arm so that the centre of the transducer overlies the brachial artery. The cuff is then automatically inflated to a preset level above systolic blood pressure. Deflation of the cuff occurs automatically at a preset rate ( $2 \mathrm{mmHg}$ per second in this study). When the cuff and brachial artery systolic pressures are the same, vibration in the arterial wall causes a Doppler shift which is read as systolic blood pressure. Diastolic pressure is recorded as the point at which pronounced diminution in arterial wall motion occurs. Both pressures are displayed separately on mercury manometers and the levels are held in each manometer until the next cycle is initiated.

\section{Subjects and methods}

The blood pressure of each subject was measured twice with each of the three sphygmomanometers. The order in which the three instruments were used was randomized. In each instance all six blood pressures were taken using the cuff supplied with the Arteriosonde, after minor modification to allow easy switching from one instrument to another. Two observers took part in the study, each reading the mercury columns to the nearest millimetre. 


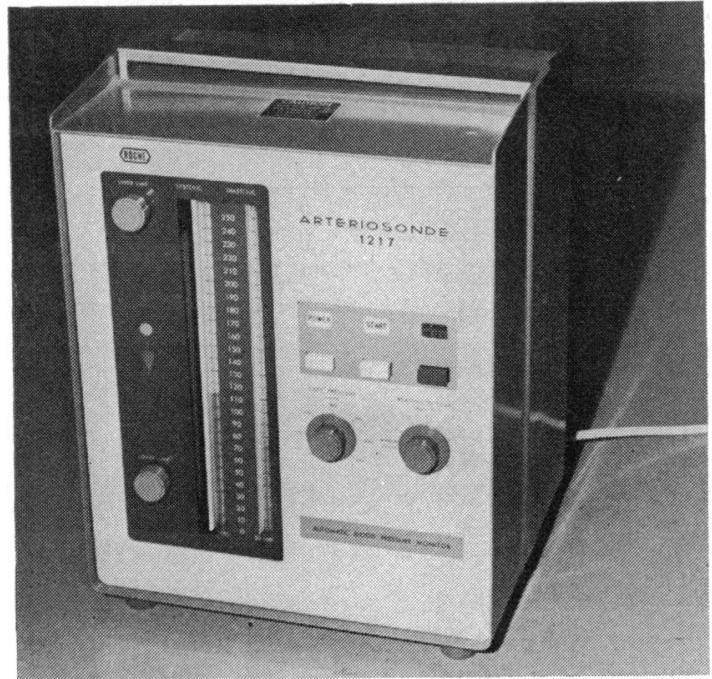

FIG. I Arteriosonde automated sphygmomanometer.

The subjects taking part in the study consisted of employees of the Hammersmith Hospital and Royal Postgraduate Medical School and patients drawn from a general surgical outpatient and two medical outpatient clinics. Blood pressures were taken from the right arm with the subject recumbent.

\section{Results}

A total of 100 pairs of blood pressure readings was taken with each instrument. Since the two observers studied different subjects their results are reported separately.

\section{Comparison of readings}

There was good agreement between the readings obtained with all three instruments (Tables I and 2),

TABLE I Average blood pressures in $\mathrm{mmHg}$ recorded with the three sphygmomanometers

\begin{tabular}{|c|c|c|c|}
\hline \multirow{2}{*}{ Observer } & \multirow{2}{*}{$\begin{array}{l}\text { Instrument } \\
\text { Arteriosonde }\end{array}$} & \multicolumn{2}{|c|}{$\begin{array}{l}\text { Average pressure } \pm S D \\
\text { (50 duplicate readings) }\end{array}$} \\
\hline & & $\begin{array}{l}\text { Systolic } \\
\text { Diastolic }\end{array}$ & $\begin{array}{r}130.77 \pm 23.28 \\
82.81 \pm 16.22\end{array}$ \\
\hline & LSHTM & $\begin{array}{l}\text { Systolic } \\
\text { Diastolic } 4 \\
\text { Diastolic } 5\end{array}$ & $\begin{array}{r}125.28 \pm 22.85 \\
86.58 \pm 14.81 \\
78.17 \pm 14.35\end{array}$ \\
\hline & Hawksley & $\begin{array}{l}\text { Systolic } \\
\text { Diastolic }\end{array}$ & $\begin{array}{r}131.80 \pm 22.93 \\
82.22 \pm 14.21\end{array}$ \\
\hline \multirow[t]{3}{*}{ B } & Arteriosonde & $\begin{array}{l}\text { Systolic } \\
\text { Diastolic }\end{array}$ & $\begin{array}{r}138.14 \pm 26.11 \\
87.42 \pm 16.09\end{array}$ \\
\hline & LSHTM & $\begin{array}{l}\text { Systolic } \\
\text { Diastolic } 4 \\
\text { Diastolic } 5\end{array}$ & $\begin{array}{r}138.41 \pm 26.03 \\
90.81 \pm 14.62 \\
82.15 \pm 19.87\end{array}$ \\
\hline & Hawksley & $\begin{array}{l}\text { Systolic } \\
\text { Diastolic }\end{array}$ & $\begin{array}{r}137.75 \pm 26.67 \\
87.01 \pm 15.77\end{array}$ \\
\hline
\end{tabular}

FIG. 2 Arteriosonde sphygmomanometer cuff showing the transducer which contains a series of ultrasonic generators and receivers. 
TABLE 2 Agreement between blood pressure readings obtained with the Arteriosonde and other sphygmomanometers

\begin{tabular}{|c|c|c|c|c|}
\hline Machine & Observer & Pressure & $\begin{array}{l}\text { Correlation } \\
\text { coefficient }\end{array}$ & Significance \\
\hline \multirow[t]{2}{*}{ Arteriosonde-Hawksley } & $\mathbf{A}$ & $\begin{array}{l}\text { Systolic } \\
\text { Diastolic }\end{array}$ & $\begin{array}{l}0.929 \\
0.897\end{array}$ & $\begin{array}{l}P<0.001 \\
P<0.001\end{array}$ \\
\hline & B & $\begin{array}{l}\text { Systolic } \\
\text { Diastolic }\end{array}$ & $\begin{array}{l}0.963 \\
0.931\end{array}$ & $\begin{array}{l}\mathbf{P}<0.001 \\
\mathbf{P}<0.001\end{array}$ \\
\hline \multirow[t]{2}{*}{ Arteriosonde - LSHTM } & $\mathbf{A}$ & $\begin{array}{l}\text { Systolic } \\
\text { Diastolic } 4 \\
\text { Diastolic } 5\end{array}$ & $\begin{array}{l}0.922 \\
0.885 \\
0.899\end{array}$ & $\begin{array}{l}P<0.001 \\
P<0.001 \\
P<0.001\end{array}$ \\
\hline & B & $\begin{array}{l}\text { Systolic } \\
\text { Diastolic } 4 \\
\text { Diastolic } 5\end{array}$ & $\begin{array}{l}0.944 \\
0.815 \\
0.748\end{array}$ & $\begin{array}{l}P<0.001 \\
P<0.001 \\
P<0.001\end{array}$ \\
\hline
\end{tabular}

TABLE 3 Average differences in $\mathrm{mmHg}$ between duplicate readings with three sphygmomanometers

\begin{tabular}{llll}
\hline Observer & Instrument & & $\begin{array}{l}\text { Difference between } \\
\text { duplicates } \pm S E\end{array}$ \\
\hline A & Arteriosonde & Systolic & $5.06 \pm 0.68$ \\
& & Diastolic & $4.86 \pm 0.79$ \\
& LSHTM & Systolic & $5.56 \pm 0.82$ \\
& Diastolic & $7.88 \pm 1.21^{\star} \dagger$ \\
& Hawksley & Systolic & $5.76 \pm 0.71$ \\
& Brteriosonde & Diastolic & $4.40 \pm 0.49$ \\
& Systolic & $4.16 \pm 0.52$ \\
& Diastolic & $5.00 \pm 0.71$ \\
& LSHTM & Systolic & $6.38 \pm 0.94^{\star}$ \\
& Diastolic & $5.14 \pm 0.70$ \\
& Hawksley & Systolic & $5.58 \pm 0.86$ \\
& & Diastolic & $4.78 \pm 0.68$
\end{tabular}

* Mean value is significantly greater than that obtained with the Arteriosonde, $\mathrm{P}<0.05$.

† Mean value is significantly greater than that obtained with the Hawksley sphygmomanometer, $\mathrm{P}<0.0$.

there being no statistically significant differences between the average values of systolic or diastolic pressure for either observer. Diastolic pressures obtained with the Arteriosonde lay midway between phase 4 and phase 5 diastolic recorded with the LSHTM sphygmomanometer. The average difference between the duplicate readings of systolic blood pressure obtained with the Arteriosonde was smaller than that for the other two instruments (Table 3) but only achieved statistical significance for observer B with the LSHTM sphygmomanometer $(t=2.06, P<0.05)$. For diastolic pressure the difference between duplicate readings was also smaller for the Arteriosonde than for the LSHTM sphygmomanometer (phase 4) and was significant for observer $A(t=2.09, P<0.05)$. The difference between the first and second readings was, however, greater for the Arteriosonde than for the Hawksley random-zero sphygmomanometer. This difference between machines was not statistically significant.

\section{Digit preference}

The frequency distribution of each terminal digit is shown in Fig. 3. There was no evidence of significant digit preference when using the LSHTM sphygmomanometer, and digit preference was reduced by the Hawksley sphygmomanometer. However, there was evidence of a high degree of preference for even digits by both observers when using the Arteriosonde.

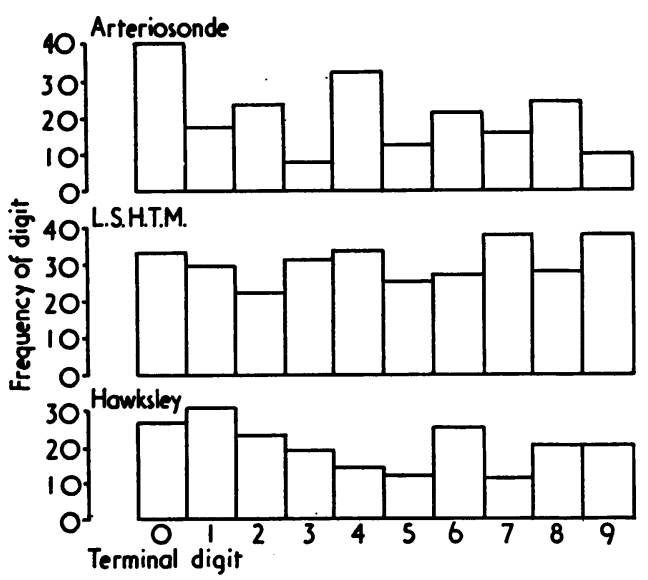

FIG. 3 Frequency distribution of terminal digits obtained using the three sphygmomanometers (observer $B)$. There is a significant preference for even terminal digits shown when using the Arteriosonde $\left(\chi^{2}=47.9\right.$, $P<0.001$ ) and with the Hawksley sphygmomanometer $\left(\chi^{2}=17.6, P<0.05\right)$. In contrast there is no significant digit preference when using the LSHTM sphygmomanometer $\left(\chi^{2}=7.7, N S\right)$. 


\section{Discussion}

Although the ultrasound sphygmomanometer has been compared with direct intra-arterial measurements (Hochberg and Salomon, I97I; Sheppard, Johnson, and Kirklin, I97I), there are no published comparisons with indirect instruments which reduce or eliminate observer bias. The present study demonstrates that the Arteriosonde gives closely similar values of systolic blood pressure to the other instruments and that diastolic blood pressure lies midway between phase 4 and phase 5 values obtained with the London School of Hygiene and Tropical Medicine sphygmomanometer. Furthermore the accuracy of duplicate measurements of systolic blood pressure is greater than that of either the LSHTM or Hawksley instruments. It is, however, interesting to note that duplicate readings of diastolic pressure obtained with the Hawksley sphygmomanometer were apparently less variable than those recorded with the other two instruments. One explanation for this finding could be that the second diastolic pressure reading obtained with the Hawksley machine is not truly blind since it will be influenced by the previous reading of pulse pressure and current systolic pressure (Grimley Evans and Prior, 1970). The advantages of the Arteriosonde are offset to some extent by the tendency to terminal digit preference. This tendency could be overcome by obtaining a digital print-out from the machine, a modification which is technically feasible.

The Arteriosonde fulfils two important requirements of an automated blood pressure monitoring system. These are, first, simplicity of use, despite the minor disadvantage of having to apply the ultrasonic coupling medium to the skin and then to remove it. The second requirement, reliability, has been confirmed by the present results and by another study where the machine was compared with intra-arterial measurements (Gundersen and Ahlgren, 1973). This experience contrasts with that of Labarthe, Hawkins, and Remington (1973) who found that the Arteriosonde 1216, the earlier model, produced readings significantly lower than the standard sphygmomanometer.
In practice, the machine has proved very useful in several clinical research projects since it provides reliable objective readings of arterial pressure and is not dependent upon the presence of a particular observer. Apart from its bulk and weight, which necessitates it being mounted on a trolley, the only major disadvantage of the machine is its cost, approximately $£ \mathrm{I} 600$.

\section{References}

Grimley Evans, J., and Prior, I. A. M. (1970). Experience with the random-zero sphygmomanometer. British fournal of Preventive and Social Medicine, 24, 10.

Gruen, W. (1968). An assessment of present automated methods of indirect blood pressure measurements. Annals of the New York Academy of Sciences, 147, 109.

Gruen, W. (1969). Automated indirect measurement of blood pressure utilizing the phase shift principle. In Proceedings of the Second Annual Conference on Automated Indirect Blood Pressure, p. 49. Ed. by P. G. Rochmis. Hoffman-La Roche, New Jersey.

Gundersen, J., and Ahlgren, I. (1973). Evaluation of an automatic device for measurement of the indirect systolic and diastolic blood pressure, Arteriosonde 1217. Acta Anaesthesiologica Scandinavica, 17, 203.

Hochberg, H. M., and Salomon, H. (197I). Accuracy of an automated ultrasound blood pressure monitor. Current Therapeutic Research, 13, 129.

Labarthe, D. R., Hawkins, C. M., and Remington, R. D. (I973). Evaluation of performance of selected devices for measuring blood pressure. American fournal of Cardiology, 32, 546.

Rose, G. A., Holland, W. W., and Crowley, E. A. (1964). A sphygmomanometer for epidemiologists. Lancet, I, 296.

Sheppard, L. C., Johnson, T. S., and Kirklin, J. W. (I97I). Controlled study of brachial artery blood pressure measured by a new indirect method. Fournal of the Association for Advances in Medical Instrumentation, 5, 297.

Ware, R. W. (1965). New approaches to the indirect measurement of human blood pressure. Presented at the Third National Biomedical Sciences Instrumentation Symposium, Dallas, Texas.

Wright, B. M., and Dore, C. F. (1970). A random-zero sphygmomanometer. Lancet, $\mathbf{r}, 337$.

Requests for reprints to Dr. C. F. George, Faculty of Medicine, Southampton General Hospital, Tremona Road, Southampton $\mathrm{SO}_{9} 4 \mathrm{XY}$. 